\title{
The Metabolic Syndrome in Treatment-Seeking Obese Persons
}

\author{
Giulio Marchesini, Nazario Melchionda, Giovanni Apolone, Massimo Cuzzolaro, Edoardo Mannucci, \\ Francesco Corica, Enzo Grossi, and the QUOVADIS Study Group
}

\begin{abstract}
Obesity is a major risk factor for several metabolic diseases, frequently clustering to form the metabolic syndrome, carrying a high risk of cardiovascular mortality. We aimed to assess the prevalence of the metabolic syndrome in treatment-seeking obese subjects and the potential protective effect of physical activity. A cross-sectional analysis of data from a large Italian database of treatment-seeking obese subjects was performed. The metabolic syndrome was defined according to the criteria provisionally set by the National Cholesterol Education Expert Panel on Detection, Evaluation, and Treatment of High Blood Cholesterol in Adults, based on waist circumference, fasting glucose, triglyceride (TG) and high-density lipoprotein-cholesterol (HDL-C) levels, and arterial pressure. Data were available in 1,889 Caucasian subjects, $78 \%$ females, from 25 obesity centers. Minimum criteria for the metabolic syndrome were fulfilled in $53 \%$ of cases. The prevalence increased with age and obesity class and was negatively associated with participation in a structured program of physical activity (odds ratio, 0.76 ; 0.58 to $0.99 ; P=.041$ ), after correction for age, sex, and body mass. The prevalence of cardiovascular disease was higher in subjects with the metabolic syndrome. A subset of $12.8 \%$ of cases had no metabolic abnormalities. They had a lower prevalence of abdominal obesity and cardiovascular disease. Isolated obesity was significantly associated with physical activity (odds ratio, 1.86; 1.33 to $2.60 ; P=.0003$ ). Multiple metabolic disorders are present in most obese patients, and their prevalence is lower in physically active subjects. It is time to move towards a more integrated approach and to reconsider resource allocation to improve lifestyle changes for large-scale control of obesity.
\end{abstract}

๑) 2004 Elsevier Inc. All rights reserved.

I N 1998, the World Health Organization $(\mathrm{WHO})^{1}$ proposed the term "Metabolic Syndrome" to define the association of several metabolic diseases (obesity, type 2 diabetes, dyslipidemia, and hypertension) all contributing to cardiovascular risk. The syndrome was previously known as syndrome $\mathrm{x},{ }^{2}$ "deadly quartet", ${ }^{3}$ plurimetabolic syndrome, or as insulin-resistance syndrome $e^{4,5}$ because of the pathogenic role of reduced insulin sensitivity. The cut offs of the various components changed during the course of years, and other features were included (hyperuricemia, defective fibrinolysis, nonalcoholic steatohepatitis $^{6}$ ), making any epidemiologic survey impossible. WHO criteria were slightly modified in 19997 to comply with the new classification of hypertension proposed by the WHOInternational Society of Hypertension. ${ }^{8}$ Unfortunately, the criteria proposed by WHO included the assessment of insulin sensitivity, hence difficult to evaluate and unsuitable for epidemiologic purposes. Only recently, the National Cholesterol Education Expert Panel on Detection, Evaluation, and Treatment of High Blood Cholesterol in Adults (Adult Treatment Panel III [ATP III] $)^{9}$ provided a working definition of the metabolic syndrome, which may be easily applied to assess its prevalence in epidemiologic studies. ${ }^{10}$

The central feature of the metabolic syndrome is obesity ${ }^{11,12}$; its spreading as a worldwide epidemic is a matter of concern in terms of population health and resource allocation. ${ }^{13} \mathrm{~A}$ high body fat mass is associated with an elevated cardiovascular risk, ${ }^{14,15}$ which increases further in the presence of additional metabolic disorders ${ }^{16}$ and is modulated by social factors and lifestyle habits (smoking, diet, physical activity). ${ }^{17}$ No systematic data are available on the prevalence of the metabolic syndrome in obese patients when assessed by the well-defined criteria proposed by ATP III.

The QUOVADIS study (QUality of life in Obesity: eVAluation and DIsease Surveillance) is a large, observational study aimed at providing a complete picture of obese patients seeking treatment of obesity at Italian medical centers. ${ }^{18}$ Several clinical and laboratory data were recorded in patients consecutively attending 25 obesity centers. The aim of the present report was to define the prevalence of the metabolic syndrome in treat- ment-seeking obese persons, its possible association with cardiovascular risk profile, and the putative protective effect of physical activity on metabolic disorders.

\section{MATERIALS AND METHODS}

\section{Patients}

During the years 1999 to 2000, 25 Italian centers with specific interest in clinical research consecutively enrolled treatment-seeking obese patients (body mass index $[\mathrm{BMI}] \geq 30 \mathrm{~kg} / \mathrm{m}^{2}$ ) in an observational study specifically aimed at measuring the burden of obesity and its complications on health-related quality of life and psychologic distress. The protocol of the study and the main features of patients have been previously reported. ${ }^{18}$ Briefly, the enrolment period was preceded by 2 meetings of the steering committee and by a general investigators' meeting to decide selection criteria, to agree on data collection, and managing of patients. All obese subjects seeking treatment were eligible for the study, provided they were not on active treatment for obesity at the time of enrolment, were in the age range between 20 and 65, agreed to fill a package of self-administered questionnaires, and signed an informed consent to participate. History taking and clinical examination were performed by means of a predefined checklist agreed by all participants. The Case Report Form included information on civil and educational status, personal and

From the Unit of Metabolic Diseases, "Alma Mater Studiorum" University of Bologna, Bologna; "Mario Negri" Institute for Pharmacological Research, Milan; Department of Psychiatry, University "La Sapienza," Rome; Department of Endocrinology and Metabolism, University of Florence, Florence; Department of Internal Medicine, University of Messina, Messina; and Medical Direction, BRACCO Imaging Spa, Milan, Italy.

Submitted April 18, 2003; accepted October 25, 2003.

The QUOVADIS Study is supported by an unrestricted grant from BRACCO Imaging Spa, Milan, Italy.

Address reprint requests to Professor Giulio Marchesini, Servizio di Malattie del Metabolismo, Università di Bologna, Azienda Ospedale S.Orsola-Malpighi, Via Massarenti 9, I-40138 Bologna, Italy.

(C) 2004 Elsevier Inc. All rights reserved.

0026-0495/04/5304-0001\$30.00/0

doi:10.1016/j.metabol.2003.10.026 
Table 1. Prevalence of the Metabolic Syndrome (95\% Cl) and Its Individual Features in Obese Patients Studied

\begin{tabular}{|c|c|c|c|c|c|c|}
\hline & $\begin{array}{c}\text { Males } \\
(n=418)\end{array}$ & $\begin{array}{c}\text { Females } \\
(n=1,471)\end{array}$ & $\begin{array}{c}\text { Total No. } \\
\text { Positive }\end{array}$ & $\begin{array}{c}\text { SENS } \\
(\%)\end{array}$ & $\begin{array}{l}\text { SPEC } \\
(\%)\end{array}$ & $\begin{array}{l}\text { PPV } \\
(\%)\end{array}$ \\
\hline Metabolic syndrome & $57(52-61)$ & $52(49-54)$ & 1,001 & & & \\
\hline Visceral adiposity [waist $>102 \mathrm{~cm}(\mathrm{M}),>88(\mathrm{~F})]$ & $94(91-96)$ & $95(93-96)$ & 1,788 & 99 & 10 & 55 \\
\hline Arterial pressure $\geq 130 / 85 \mathrm{~mm} \mathrm{Hg}$ or antihypertensive treatment & $78(74-82)$ & $64(62-67)^{*}$ & 1,273 & 89 & 57 & 70 \\
\hline Triglycerides $>1.70 \mu \mathrm{mol} / \mathrm{L}$ or fibrate-treated & $45(40-50)$ & $26(24-29)^{*}$ & 577 & 50 & 92 & 87 \\
\hline HDL-cholesterol $<1.03 \mu \mathrm{mol} / \mathrm{L}(\mathrm{M}),<1.29 \mu \mathrm{mol} / \mathrm{L}(\mathrm{F})$ & $32(27-36)$ & $54(51-56)^{*}$ & 921 & 71 & 77 & 78 \\
\hline
\end{tabular}

NOTE. The SENS, SPEC, and PPV for the diagnosis of the metabolic syndrome are also reported.

Abbreviations: SENS, sensitivity, SPEC, specificity; PPV, predictive value of positive results.

*Significantly different from the prevalence reported in male gender.

family history of metabolic and cardiovascular diseases, as well as previous and current pharmacologic treatment. Recorded data also comprised cigarette smoking and alcohol consumption and participation in a structured program of physical activity. Any type of physical activity was considered, including brisk walking, either under supervision of an exercise trainer or self-organized, provided patients exercised for a minimum of 30 minutes, at least twice a week. To expedite handling of data, the study was totally web-based, through an extranet system provided by CINECA (Casalecchio di Reno, Italy), using the AMR (Advanced Multicenter Research) methodology, developed by CINECA as a result of an extensive cooperation of clinicians, statisticians, and informatics. The management of whole data was performed by standard web-browsers, and the quality level was guaranteed by upfront quality controls (on client side) and consistency checks (on server side).

By December 2001, when the enrolment was closed, the web-based database stored clinical and laboratory data of 1,944 obese subjects of Caucasian origin, but complete data to calculate the prevalence of the metabolic syndrome were available only in 1,889 cases. Median age was 45 years. The large majority of subjects were females $(n=1,470$ [77.9\%]; 564 [38.2\%] postmenopausal). Their average BMI was $38.1 \pm \mathrm{SD} 6.4 \mathrm{~kg} / \mathrm{m}^{2}$ (range, 30.0 to 82.2 ). The distribution according to obesity class was: BMI 30.0 to $34.9, \mathrm{n}=725(38.4 \%)$; BMI 35.0 to $39.9, \mathrm{n}=534(28.3 \%)$; BMI $\geq 40.0, \mathrm{n}=630$ (33.4\%). Coronary heart and peripheral vascular diseases were investigated by clinical examination, history, previous electrocardiogram (ECG) recordings, and pharmacologic treatment; no systematic screening with ECG or Doppler ultrasounds was performed at the time of study.

Diabetes had been previously diagnosed in $12.7 \%$ of males $(95 \%$ confidence interval [CI], 9.7 to 16.1 ) and in $8.3 \%$ (7.0 to 9.8) of females $(P=.008)$. Hypertension was treated in $43.5 \%$ (38.7 to 48.2$)$ of males and $34.5 \%$ (32.1 to 36.9$)$ of females $(P=.078)$. Only $6.2 \%$ of males and $2.4 \%$ of females were being treated with fibrates or statins.

In a subset of 712 patients (559 females), 120-minute blood glucose values in the course of an oral glucose tolerance test were also available.

\section{Methods}

Body weight was measured in light clothing and without shoes to the nearest half kilogram. Height was measured to the nearest half centimeter. Waist circumference was measured at the nearest half centimeter at the shortest point below the lower rib margin and the iliac crest, whereas hip circumference was similarly obtained at the widest point between hip and buttocks.

Blood pressure measurements were obtained according to Guidelines of the International Society of Hypertension. ${ }^{8}$ Three blood pressure readings were obtained at 1-minute intervals, and the second and third systolic and diastolic pressure readings were averaged and used in the analyses.
Plasma glucose, both in the fasting state and in response to a standard glucose load, total cholesterol (CHOL), high-density lipoprotein-cholesterol (HDL-C), and triglycerides (TG) were measured in individual centers at the time of enrollment by common standard laboratory techniques (CHOL, HDL-C plus [2nd generation], and TG assays [Roche Diagnostics, Indianapolis, IN]).

The prevalence of the metabolic syndrome was calculated according to the ATP III proposal, ${ }^{9}$ as the presence of 3 or more of the following criteria: (1) abdominal obesity: waist circumference $>102 \mathrm{~cm}$ in males and $>88 \mathrm{~cm}$ in females; (2) hypertriglyceridemia: $\geq 1.7 \mathrm{mmol} / \mathrm{L}$; (3) low HDL-C: $<1.03 \mathrm{mmol} / \mathrm{L}$ in males and $<1.29 \mathrm{mmol} / \mathrm{L}$ in females; (4) high blood pressure: $\geq 130 / 85 \mathrm{~mm} \mathrm{Hg}$; (5) fasting hyperglycemia (impaired fasting glucose [IFG]) $\geq 110 \mathrm{mg} / \mathrm{dL}$. In addition, all subjects with a previous diagnosis and regularly treated for hypertension, diabetes, or hypertriglyceridemia with fibrates were considered to fit the respective criteria, independently of measured values. In subjects no longer on active treatment, only measured values were considered.

\section{Statistical Analysis}

Differences in individual parameters between groups were analyzed by Student's $t$ test or Mann-Whitney test, whenever appropriate. The $\chi^{2}$ test was used to compare prevalence between groups. Logistic regression analysis (both univariate and multivariate) was used to identify factors significantly associated with the presence of the metabolic syndrome (dependent variable) after adjustment for age and sex. Participation in a structured program of physical activity, smoking habits, and alcohol consumption were additional independent variables. The odds ratio (OR), the $95 \%$ confidence limits, and $P$ values were calculated. All analyses were performed on a personal computer and StatView5 program (ABACUS Concepts, Berkeley, CA.) or SPSS/PC+ 4.0 package (SPSS, Chicago, IL.).

\section{RESULTS}

BMI and obesity class distribution were not different between genders (Table 1). A total of 725 patients had class I obesity (BMI: 30 to $34.9 \mathrm{~kg} / \mathrm{m}^{2}$ ), 534 had class II obesity (35 to 39.9$), 630$ had class III obesity ( $\geq 40$ ). Male patients had higher fasting and postload glucose, higher TG levels, and lower HDL-C. Also systolic and diastolic pressure readings were higher.

The waist criteria for abdominal obesity were fulfilled in nearly all cases without differences between genders. Only $5 \%$ of patients with class I obesity had waist girth below the cut off.

The prevalence of the other features of the metabolic syndrome was also very high. Hypertension was the most common finding; blood pressure levels $\geq 130 / 85 \mathrm{~mm} \mathrm{Hg}$ were measured in $48.7 \%$ of patients without a previous diagnosis of hyperten- 


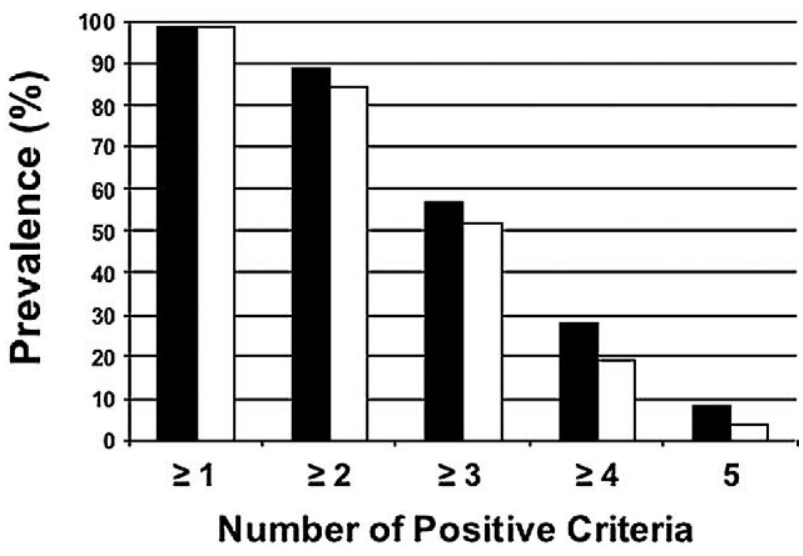

Fig 1. Prevalence of positive criteria for the metabolic syndrome in obese subjects. Closed columns, males; open columns, females.

sion. Incidentally, blood pressure exceeded normal limits in $77.8 \%$ (74.5 to 80.7 ) of patients with previously diagnosed hypertension.

At least 1 criterion for the metabolic syndrome was fulfilled in over $99 \%$ of cases (Fig 1); 1,001 patients $(53.0 \%$; $95 \% \mathrm{CI}$, 50.7 to 55.2 ) fulfilled 3 or more criteria and could be identified as having the metabolic syndrome, without differences in relation to gender (males, 56.7\%; females, 51.9; $P=.08$ ). The prevalence of the metabolic syndrome increased with increasing BMI (Fig 2, top panel), being 43.6\% (40.0 to 47.1) in class I obesity, $51.1 \%$ (46.8 to 55.2 ) in class II, and $65.5 \%$ (61.6 to 69.0) in class III $(P<.0001)$. Obesity-related changes were more marked in females $\left(\chi^{2} ; P<.0001\right)$ than in males $(P=$

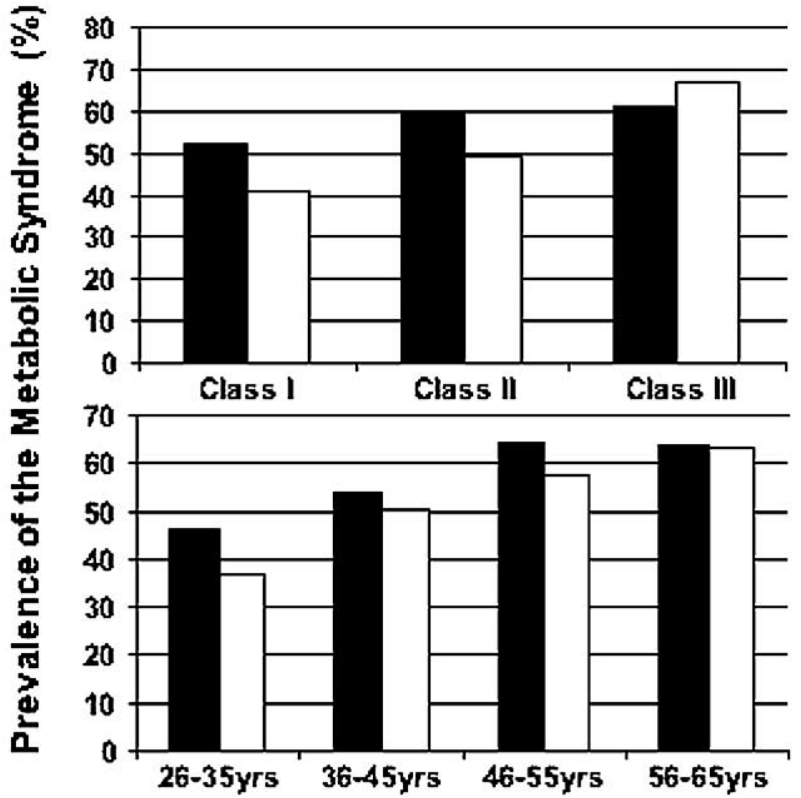

Fig 2. Prevalence of the metabolic syndrome in obesity according to obesity class (class I, BMI 30 to 34.9; class II, BMI 35 to 39.9; class III, BMI $\geq 40$ ) and age. Closed columns, males; open columns, females.

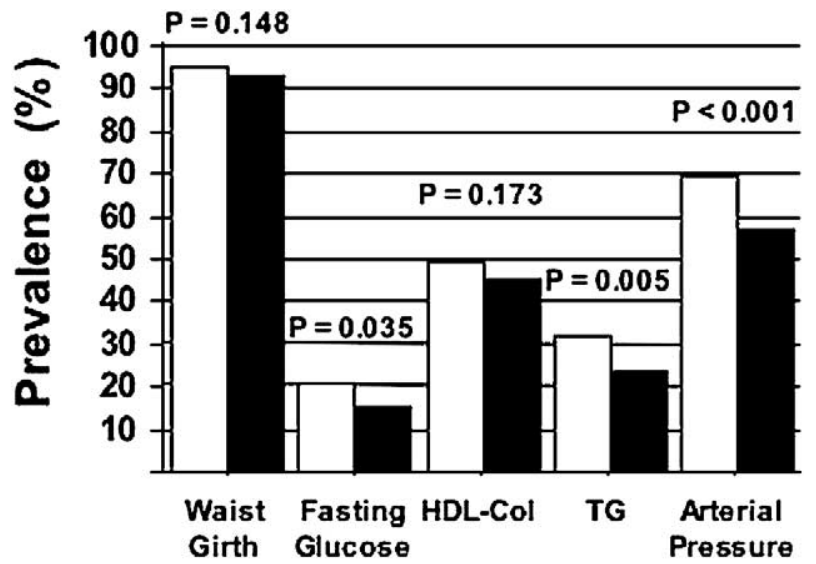

Fig 3. Prevalence of positive criteria for the metabolic syndrome in obese subjects. Open columns, sedentary cases; closed columns, subjects involved in physical activity. TG, triglycerides.

.259). Prevalence also increased with age (Fig 2, bottom panel), from $38.8 \%$ (34.3 to 43.2$)$ in the age range $<35$ years to $63.3 \%$ (58.1 to 68.0) in the age group 56 to 65 years $(P=.022$ in males and $P<.0001$ in females).

The practice of regular, structured physical activity was reported by $14.7 \%$ of patients (95\% CI, 13.2 to 16.4 ), without differences in relation to gender (males, 13.6\%; females, $15.0 \% ; P=.531$, Fisher's exact test). The median weekly time spent in physical activity was 2 hours (range, 1 to 14). The prevalence of all criteria for the metabolic syndrome was reduced in these patients (Fig 3). Alcohol consumption was reported in $20.5 \%$ (18.7 to 22.4 ), cigarette smoking in $22.4 \%$ (20.5 to 24.3), more frequently in males ( $P<.0001 v$ females).

Altered glucose metabolism was the most specific factor predicting the presence of a metabolic syndrome in obese persons (Table 1), followed by increased TG, whereas increased arterial pressure had the highest sensitivity.

At logistic regression analysis, the metabolic syndrome was positively associated with age (OR, $1.43 ; 1.32$ to 1.56 per 10 years; $P<.0001$ ), BMI (OR, $1.37 ; 1.27$ to 1.48 per $5 \mathrm{~kg} / \mathrm{m}^{2}$; $P<.0001)$, and negatively with participation in a structured program of physical activity (OR, $0.63 ; 0.49$ to $0.81 ; P=$ .0004). In multivariate analysis, after correction for age, sex, and BMI, cigarette smoking and alcohol consumption were not associated with the metabolic syndrome, whereas structured physical activity maintained a negative association (OR, 0.76; 0.58 to $0.99 ; P=.041)$.

A previous diagnosis of coronary heart disease was reported in 49 patients. The prevalence was higher in males $(5.7 \%, 95 \%$ CI, 3.8 to $8.3 \vee 1.7 \%, 1.2$ to 2.5 in females; $P<.0001)$. Thirteen males and 13 females reported a previous myocardial infarction, 3 males and 3 females a previous coronary bypass. Only 3 patients reported a peripheral vascular disease treated by femoral bypass or carotid surgery. The prevalence of cardiovascular disease (any event) was $4.0 \%$ (95\% CI, 2.9 to 5.3) in subjects with the metabolic syndrome and only $1.0 \%(95 \%$ CI, 0.5 to 1.8 ) in subjects not fitting the criteria of ATP III.

Finally, 241 of 1,889 obese patients $(12.8 \%, 95 \%$ CI, 11.3 to 14.3) had normal glucose and lipid levels and normal blood 
pressure. Their age and obesity class distribution was significantly skewed when compared with the total group towards younger age $(P<.0001)$ and lower obesity class $(P<.0001)$. One hundred and fifty-two patients were less than 45 years old (63\%), $131(54 \%)$ belonged to obesity class I, $69(28 \%)$ to obesity class II. Twenty-eight cases $(11.6 \%)$ had a waist circumference below the ATP III cut off. The prevalence of cardiovascular disease was low $(1.7 \%, 0.5$ to 3.9$)$. In only 10 of $91(11 \%)$, the oral glucose tolerance test was indicative of impaired glucose tolerance, compared with a prevalence of impaired glucose tolerance or diabetes after glucose load of $27 \%$ in the remaining 621 cases. They were more frequently involved in structured physical activity (25\% v $13 \%$ in subjects with additional metabolic disorders; $P<.0001$; Fisher's exact test).

At logistic regression analysis, isolated obesity was significantly associated with younger age (OR, $0.70 ; \mathrm{CI}, 0.61$ to 0.79 per 10 years; $P<.0001$ ), with female sex (OR, $0.69 ; 0.48$ to $0.99 ; P=.041$ ), with lower BMI (OR, $0.67 ; 0.59$ to $0.77 ; P<$ $.0001)$, and with physical activity (OR, $2.23 ; 1.62$ to $3.09 ; P<$ $.0001)$. At multivariate analysis, the positive association with physical activity was maintained after correction for age, gender, and BMI (OR, $1.86 ; 1.33$ to $2.60 ; P=.0003)$.

\section{DISCUSSION}

The present analysis identifies obesity as a multifaceted disease in which several metabolic abnormalities contribute to increase cardiovascular risk profile. Our prevalence of the metabolic syndrome in obesity refers to the specific subgroups of obese patients seeking treatment at obesity centers. It may be overestimated when compared with the general obese population, because of the referral bias to medical centers, where patients with complications are more likely to be addressed. On the other hand, the prevalence might be underestimated when compared with subjects treated in cardiology units. The relatively low prevalence of cardiovascular disease observed in the present series suggests that most patients with coronary heart disease do not seek treatment for losing weight at obesity centers.

Another source of error might be the definition of altered glucose metabolism without considering impaired glucose tolerance according to WHO criteria. ${ }^{1}$ In a large cohort of 1,428 nondiabetic obese subjects, isolated impaired glucose tolerance was reported in $15 \%$ to $20 \%$ of cases. ${ }^{19}$ In the subgroup of the 712 patients submitted to an oral glucose load, the inclusion of impaired glucose tolerance as screening criterion increased the overall prevalence of altered glucose metabolism from $24 \%$ to $36 \%$ and the final prevalence of the metabolic syndrome from $55 \%$ to $58 \%$. In the presence of obesity, altered carbohydrate metabolism was the most specific metabolic abnormality for the prediction of the metabolic syndrome, and a correct evaluation in obese persons is mandatory. Also ATP III acknowledges the high cardiovascular risk associated with diabetes, and its presence is considered to confer a risk equivalent to established coronary heart disease and other clinical forms of atherosclerotic disease, although a recent study has challenged this conclusion. ${ }^{20}$ The combined effects of the obesity epidemic and population ageing, by increasing the prevalence of diabetes, ${ }^{21}$ will end up in a dramatic increase in the prevalence of the metabolic syndrome and correlated cardiovascular disease in the next decades, hence the need for correct assessment of the population at risk.

Hypertension was exceedingly common in our series, but its link with the metabolic syndrome was not as strong as the one of diabetes. The ATP III proposal considers the very strict cut off of normal blood pressure, ${ }^{8}$ a limit that is very frequently overcome in the general population and very rarely achieved by treatment in general practice, ${ }^{22,23}$ and also in hypertension clinics in Italy. ${ }^{24}$ Hypertension has been associated with insulin resistance, ${ }^{25}$ which is considered the pathogenic factor of the metabolic syndrome. ${ }^{26}$ However, there is evidence that hypertension is not as strongly linked to the metabolic syndrome as other variables, ${ }^{27}$ although maintaining an independent effect. ${ }^{28}$

The 2 lipid criteria identified 2 slightly different populations. Whereas the cut off for raised TG was more frequently fulfilled in males, a reduced HDL was more common in females. A lipid factor was previously identified as principal component of the metabolic syndrome in males, but not in the general female population. ${ }^{11}$ The presence of diabetes, in which lipid levels may change according to metabolic control, ${ }^{29}$ may be an additional confounding factor. The inclusion of subjects treated with statins in the low HDL-C group may be considered inappropriate. However, these patients were a minority, and their exclusion does not change the results significantly.

Although our population had a low prevalence of cardiovascular disease, data are consistent with the metabolic syndrome being associated with a higher prevalence of cardiovascular events. Similar data have been obtained in several studies in the general population ${ }^{16,30,31}$ and also in patients with diabetes, ${ }^{32}$ when the prevalence of the syndrome was assessed using the WHO criteria. ${ }^{7}$ The risk is increased independently of ethnic origin. ${ }^{33}$ Follow-up studies are needed to confirm the retrospective results we obtained in our Caucasian population.

The most relevant finding of the present cross-sectional study is the negative association of structured physical activity with the prevalence of the metabolic syndrome. These data are in agreement with a recent study in obese women ${ }^{34}$ and with intervention studies on the prevention of diabetes. ${ }^{35-37}$ They proved that behavior modifications are achievable and effective in reducing the risk of diabetes by lifestyle changes. The goal was achieved by a modest reduction of body weight (7\% to $10 \%$ ) through the combined effects of dietary restriction and increased physical exercise. Per se, physical exercise effectively reduces TG levels and increases HDL-C, 38,39 thus decreasing the prevalence of features of the metabolic syndrome at multiple levels. The finding that the protective role of structured physical activity is maintained after correction for age, gender, and BMI is in keeping with this consideration. Physical activity does not need to be strenuous and time devoted to exercise does not need to be prolonged to achieve benefits. ${ }^{40}$ The median time spent in exercise was only 2 hours per week in our series, and minimum lifestyle changes are needed to achieve this goal.

Interestingly, our study also identifies a small group of obese persons without metabolic involvement (isolated obesity). Sims ${ }^{41}$ recently proposed that a subgroup of obese, metabolically normal subjects really exists, whose uncomplicated obesity is not accompanied by insulin resistance, ${ }^{42}$ and is not associated with an increased cardiovascular risk. ${ }^{43} \mathrm{~A}$ few of 
these patients do not fit the criteria of abdominal obesity, despite a BMI in the obesity range. Follow-up and genetic studies in this subset are needed to verify whether this condition is a temporary one, as age and obesity class dependency might suggest, or it stems from a different, potentially protective genotype. Also in this case, lifestyle changes might be relevant as preventive or therapeutic measures, as supported by the close association of isolated obesity with the participation in structured programs of physical activity, after correction for obesity and personal data.

In summary, our data underline the high prevalence of metabolic disorders associated with obesity to produce the metabolic syndrome. This clustering of diseases has clinical implications due to the continuing increase of obesity ${ }^{44}$ and obesity-related diseases ${ }^{45}$ in western countries. A separate pharmacologic treatment of the different components of the metabolic syndrome is expensive, ${ }^{46}$ risky because of interactions, largely ineffective to achieve desired target values, as also shown in the present series, and finally, unaffordable by any health care system. ${ }^{13}$ It is time for the medical community to move towards a more integrated approach and for health care providers to reconsider resource allocation to a large scale control of obesity, based on lifestyle changes. Any intervention in this area may be extremely cost effective.

\section{APPENDIX A}

\section{A.1. List of Participants in the QUOVADIS Study}

Coordinator: N. Melchionda, Bologna.

Steering Committee: N. Melchionda, G. Marchesini (Università di Bologna), G. Apolone (Istituto di Ricerche Farmaco- logiche "Mario Negri," Milano), M. Cuzzolaro (Università di Roma "La Sapienza”), E. Mannucci (Università di Firenze), E. Grossi (BRACCO Imaging Spa, Milano).

List of Participants: S. Avagnina, ${ }^{*}$ L. Ferrero (Torino 1, 100 cases), E.G. Barantani,* E. Molinari,* M.L. Petroni,* R.M. Marsala, A. Compare, S. Hacker (Piancavallo, 157), F. Belfiore,* (Catania, 6), F. Caviezel,* B. Ambrosi,* A. Tufano (Milano 1, 56), F. Corica, ${ }^{*}$ A. Corsonello, D. De Domenico (Messina, 80), M. Cuzzolaro,* V. Giancotti, M. Valentini, S. Antonini (Roma 1, 146), E. Dall'Aglio,* A. Adami (Parma, 64), R. Dalle Grave,* C. Scutari (Garda, 41), G. Del Rio,* M. Bondi, R. Menozzi (Modena 1, 100), G. Fatati,* M. Palazzi (Terni, 53), M.A. Fusco,* M.G. Carbonelli (Roma 2, 54), M. Gennaro, * L. Scaglione, K. Rossin (Sanremo, 73), L. Lucchin,* R. Trovato (Bolzano, 30), G. Marchesini,* L. Baraldi, G. Forlani, S. Natale, N. Villanova (Bologna, 202), A.M. Ciccarone, ${ }^{*}$ K. Chatzianagnostou (Pisa, 89), R.F. Novi,* A. Trombetta, M.A. Seardo, G.F. Alberto (Torino 2, 105), A.E. Pontiroli,* A. Saibene, P. Vedani (Milano 2, 69), C. Rotella,* S. Ciani, T. Zucchi (Firenze, 91), G. Salvioli,* P. Ventura, L. Morselli (Modena 2, 70), F. Tomasi,* S. Barbieri, E. Scalambra (Ferrara, 150), F. Capani,* E. Vitacolonna, M. Taraborrelli (Chieti, 50), C. Noacco, ${ }^{*}$ C. Taboga, S. Mreule (Udine, 60), E. Ferrari, * F. Magri (Pavia, 60), P. Beck Peccoz, ${ }^{*}$ P.S. Morpurgo (Milano 3, 53), M. De Rosa, A. Covezzoli, F. Campana (CINECA, Bologna), E. Grossi, G. Rivolta, D. Cerutti (BRACCO Imaging spa, Milano).

*Principal Investigator. The number of cases enrolled in each center is in parentheses.

\section{REFERENCES}

1. Alberti KG, Zimmet PZ: Definition, diagnosis and classification of diabetes mellitus and its complications. Part 1: Diagnosis and classification of diabetes mellitus. Provisional report of a WHO consultation. Diabet Med 15:539-553, 1998

2. Reaven GM: Banting lecture 1988. Role of insulin resistance in human diabetes. Diabetes 37:1595-1607, 1988

3. Kaplan NM: The deadly quartet. Upper-body obesity, glucose intolerance, hypertriglyceridemia, and hypertension. Arch Intern Med 149:1514-1520, 1989

4. Caro JF: Insulin resistance in obese and nonobese man. J Clin Endocrinol Metab 73:691-695, 1991

5. Wajchenberg BL, Malerbi DA, Rocha MS, et al: Syndrome X: A syndrome of insulin resistance. Epidemiological and clinical evidence. Diabetes Metab Rev 10:19-29, 1994

6. Marchesini G, Brizi M, Bianchi G, et al: Nonalcoholic fatty liver disease: A feature of the metabolic syndrome. Diabetes 50:1844-1850, 2001

7. WHO Consultation: Definition, diagnosis and classification of diabetes mellitus and its complications. World Health Organization, Geneva, Switzerland, 1999, pp 31-33

8. Guidelines Subcommittee: 1999 World Health Organization-International Society of Hypertension guidelines for the management of hypertension. J Hypertens 17:151-183, 1999

9. Expert Panel on Detection Evaluation and Treatment of High Blood Cholesterol in Adults: Executive summary of the Third Report of the National Cholesterol Education Program (NCEP) Expert Panel on Detection, Evaluation, and Treatment of High Blood Cholesterol in Adults (Adult Treatment Panel III). JAMA 285:2486-2497, 2001
10. Ford ES, Giles WH, Dietz WH: Prevalence of the metabolic syndrome among US adults: Findings from the third National Health and Nutrition Examination Survey. JAMA 287:356-359, 2002

11. Maison P, Byrne CD, Hales CN, et al: Do different dimensions of the metabolic syndrome change together over time? Evidence supporting obesity as the central feature. Diabetes Care 24:1758-1763, 2001

12. Anderson PJ, Critchley JA, Chan JC, et al: Factor analysis of the metabolic syndrome: Obesity vs insulin resistance as the central abnormality. Int J Obes Relat Metab Disord 25:1782-1788, 2001

13. World Health Organization: Preventing and managing the global epidemic: Report of a WHO consultation. World Health Organization, Geneva, Switzerland, 2000

14. Rashid MN, Fuentes F, Touchon RC, et al: Obesity and the risk for cardiovascular disease. Prev Cardiol 6:42-47, 2003

15. Bonow RO, Eckel RH: Diet, obesity, and cardiovascular risk. N Engl J Med 348:2057-2058, 2003

16. Isomaa $\mathrm{B}$, Almgren $\mathrm{P}$, Tuomi $\mathrm{T}$, et al: Cardiovascular morbidity and mortality associated with the metabolic syndrome. Diabetes Care 24:683-689, 2001

17. Lidfeldt J, Nyberg P, Nerbrand C, et al: Socio-demographic and psychosocial factors are associated with features of the metabolic syndrome. The Women's Health in the Lund Area (WHILA) study. Diabetes Obes Metab 5:106-112, 2003

18. Melchionda N, Marchesini G, Apolone G, et al: The QUOVADIS study. Features of obese Italian patients seeking treatment at specialist centers. Diabetes Nutr Metab 16:115-124, 2003

19. Melchionda N, Forlani G, Marchesini G, et al: WHO and ADA 
criteria for the diagnosis of diabetes mellitus in relation to body mass index. Insulin sensitivity and secretion in resulting subcategories of glucose tolerance. Int J Obes Relat Metab Disord 26:90-96, 2002

20. Evans JM, Wang J, Morris AD: Comparison of cardiovascular risk between patients with type 2 diabetes and those who had had a myocardial infarction: Cross sectional and cohort studies. BMJ 324: 939-942, 2002

21. Boyle JP, Honeycutt AA, Narayan KM, et al: Projection of diabetes burden through 2050: Impact of changing demography and disease prevalence in the U.S. Diabetes Care 24:1936-1940, 2001

22. Hyman DJ, Pavlik VN: Characteristics of patients with uncontrolled hypertension in the United States. N Engl J Med 345:479-486, 2001

23. He J, Muntner P, Chen J, et al: Factors associated with hypertension control in the general population of the United States. Arch Intern Med 162:1051-1058, 2002

24. Cuspidi C, Lonati L, Sampieri L, et al: Blood pressure control in a hypertension hospital clinic. J Hypertens 17:835-841, 1999

25. Ferrannini E, Buzzigoli G, Bonadonna R, et al: Insulin resistance in essential hypertension. N Engl J Med 317:350-357, 1987

26. DeFronzo RA, Ferrannini E: Insulin resistance. A multifaceted syndrome responsible for NIDDM, obesity, hypertension, dyslipidemia, and atherosclerotic cardiovascular disease. Diabetes Care 14:173194, 1991

27. Meigs JB: Invited commentary: Insulin resistance syndrome? Syndrome X? Multiple metabolic syndrome? A syndrome at all? Factor analysis reveals patterns in the fabric of correlated metabolic risk factors. Am J Epidemiol 152:908-911, 2000

28. Sakkinen PA, Wahl P, Cushman M, et al: Clustering of procoagulation, inflammation, and fibrinolysis variables with metabolic factors in insulin resistance syndrome. Am J Epidemiol 152:897-907, 2000

29. U.K. Prospective Diabetes Study 27: Plasma lipids and lipoproteins at diagnosis of NIDDM by age and sex. Diabetes Care 20:16831687, 1997

30. Lakka HM, Laaksonen DE, Lakka TA, et al: The metabolic syndrome and total and cardiovascular disease mortality in middleaged men. JAMA 288:2709-2716, 2002

31. Resnick HE, Jones K, Ruotolo G, et al: Insulin resistance, the metabolic syndrome, and risk of incident cardiovascular disease in nondiabetic american indians: The Strong Heart Study. Diabetes Care 26:861-867, 2003

32. Isomaa $\mathrm{B}$, Henricsson $\mathrm{M}$, Almgren $\mathrm{P}$, et al: The metabolic syndrome influences the risk of chronic complications in patients with type II diabetes. Diabetologia 44:1148-1154, 2001
33. Meigs JB, Wilson PW, Nathan DM, et al: Prevalence and characteristics of the metabolic syndrome in the San Antonio Heart and Framingham Offspring Studies. Diabetes 52:2160-2167, 2003

34. Irwin ML, Ainsworth BE, Mayer-Davis EJ, et al: Physical activity and the metabolic syndrome in a tri-ethnic sample of women. Obes Res 10:1030-1037, 2002

35. Pan XR, Li GW, Hu YH, et al: Effects of diet and exercise in preventing NIDDM in people with impaired glucose tolerance. The Da Qing IGT and Diabetes Study. Diabetes Care 20:537-544, 1997

36. Tuomilehto J, Lindstrom J, Eriksson JG, et al: Prevention of type 2 diabetes mellitus by changes in lifestyle among subjects with impaired glucose tolerance. N Engl J Med 344:1343-1350, 2001

37. Knowler WC, Barrett-Connor E, Fowler SE, et al: Reduction in the incidence of type 2 diabetes with lifestyle intervention or metformin. N Engl J Med 346:393-403, 2002

38. Kronenberg F, Pereira MA, Schmitz MK, et al: Influence of leisure time physical activity and television watching on atherosclerosis risk factors in the NHLBI Family Heart Study. Atherosclerosis 152: 433-443, 2000

39. Couillard C, Despres JP, Lamarche B, et al: Effects of endurance exercise training on plasma HDL cholesterol levels depend on levels of triglycerides: Evidence from men of the Health, Risk Factors, Exercise Training and Genetics (HERITAGE) Family Study. Arterioscler Thromb Vasc Biol 21:1226-1232, 2001

40. Kraus WE, Houmard JA, Duscha BD, et al: Effects of the amount and intensity of exercise on plasma lipoproteins. N Engl J Med 347:1483-1492, 2002

41. Sims EA: Are there persons who are obese, but metabolically healthy? Metabolism 50:1499-1504, 2001

42. Ferrannini E, Natali A, Bell P, et al: Insulin resistance and hypersecretion in obesity. J Clin Invest 100:1166-1173, 1997

43. Bonora E, Kiechl S, Willeit J, et al: Prevalence of insulin resistance in metabolic disorders: The Bruneck Study. Diabetes 47: 1643-1649, 1998

44. Rosengren A, Eriksson H, Larsson B, et al: Secular changes in cardiovascular risk factors over 30 years in Swedish men aged 50: The study of men born in 1913, 1923, 1933 and 1943. J Intern Med 247:111-118, 2000

45. Mokdad AH, Ford ES, Bowman BA, et al: Prevalence of obesity, diabetes, and obesity-related health risk factors, 2001. JAMA 289:76-79, 2003

46. Ray GT, Collin F, Lieu T, et al: The cost of health conditions in a health maintenance organization. Med Care Res Rev 57:92-109, 2000 